\title{
Haemophagocytic lymphohistiocytosis in Adult- A Case Report and Literature Review
}

\author{
SF HOSSAIN $^{\mathrm{a}}$, NK QURESHI ${ }^{\mathrm{b}}$, Z MAHMUD ${ }^{\mathrm{c}}$, MI HOSSAIN ${ }^{\mathrm{d}}$
}

\begin{abstract}
Summary:
Haemophagocytic lymphohistiocytosis $(\mathrm{HLH})$ is a rare but potentially fatal disease of normal but overactive histiocytes and lymphocytes that commonly appears in infancy, although it has been seen in all age groups. The disease may be inherited or acquired due to infections, collagen vascular diseases and malignancies. The pathological hallmark of the syndrome is uncontrolled activation of $T$ lymphocytes and macrophages, together with an impaired cytotoxic function of NK cells and CD8+ T lymphocytes, resulting into massive cytokine release (e.g., interferon ", TNF á, interleukin[IL]-6, 8,10,12,18 etc) from these cells and overwhelming inflammation. Lymphocytes and macrophages, sometimes with haemophagocytic activity accumulate in bone marrow, spleen, liver, or lymph nodes.
\end{abstract}

\section{Introduction:}

Haemophagocytic lymphohistiocytosis (HLH) is a rare and frequently fatal syndrome of pathological immune activation, characterized by unregulated histiocyte proliferation and hypercytokinemia. ${ }^{1}$ It comprises two different conditions, a primary or genetic ${ }^{2}$ and a secondary or acquired form ${ }^{3}$ which may be difficult to distinguish one from another. The primary autosomal recessive form, also known as familial haemophagocytic lymphohistiocytosis (FHLH), is usually seen among children though adult cases have been reported. ${ }^{4}$ FHLH were first reported among in two siblings in $1952^{5}$ and has an estimated incidence of 1 case per 50,000 liveborn children. ${ }^{6}$ This variety is a fatal disease with a

a. Dr. Syeda Fahmida Hossain, Specialist, Department of Medicine, United Hospital Limited, Dhaka, Bangladesh

b. Dr. Nazmul Kabir Qureshi, Specialist, Department of Medicine, United Hospital Limited, Dhaka, Bangladesh

c. Dr. Brig (Rtd) Zahid Mahmud, Consultant, Department of Hematology, United Hospital Limited, Dhaka, Bangladesh

d. Dr. Md Iqbal Hossain, Consultant, Department of Medicine, United Hospital Limited, Dhaka, Bangladesh

Address of Correspondence: Dr. Syeda Fahmida Hossain, Specialist, Department of Medicine, United Hospital Limited, Dhaka, Bangladesh, Phone: 01714097086. Email: sfhossain_dmc@yahoo.com

Received: 28 December, 2013 Accepted: 23 December, 2014
This immune dysregulatory disorder is characterized by fever, hepatosplenomegaly, lymphadenopathy, skin rash, cytopenias, hepatitis, coagulopathy, neurological symptoms. We report a case of 65 years old male presenting with fever and erythroderma who developed typical clinical and laboratory findings consistent with diagnosis of $\mathrm{HLH}$ according to $\mathrm{HLH}-2004$ guidelines. Despite receiving etoposide based chemotherapy, the patient succumbed rapidly from progressive $\mathrm{HLH}$. This case high lightened the diagnostic challenge and the need for keeping a high index of suspicion for promptly diagnosis and treatment of this potentially life threatening condition as clinical features and laboratory investigations are non specific.

Key words: Haemophagocytic lymphohistiocytosis.

(J Banagladesh Coll Phys Surg 2015; 33: 166-176)

median survival less than 2 months after diagnosis if untreated, and it typically has its onset during infancy or early childhood. ${ }^{7}$ Despite its name, family history is often negative since the disease is recessive and its onset may be triggered by infections as well. ${ }^{8}$ Secondary (sHLH) or acquired HLH was first established as a distinct clinico-pathological entity by Risdall in $1979^{25}$ which is more common among adults and typically occurs after strong immunological triggers that may occur with a variety of viral, bacterial, fungal, parasitic infections, collagen-vascular diseases, ${ }^{9-12}$ and malignancies, particularly T-cell lymphomas. ${ }^{13-16}$ Considering association, infection is important in both sporadic and familial cases. HLH may often mimic infectious illnesses, such as overwhelming bacterial sepsis and leptospirosis; ${ }^{17}$ and may also obscure the diagnosis of a precipitating, treatable infectious illness (as reported for visceral leishmaniasis). ${ }^{18}$ We report a case of HLH in adult in order to illustrate the spectrum of clinical features and to emphasis the importance of prompt diagnosis and initiation of therapy.

\section{Case Report:}

A 65-years-old male, known patient of hypertension, diabetes mellitus, coronary artery disease (triple vessel disease with left main), had CABG (one month past) was admitted into Medicine department of United 
Hospital Limited in June 2013 with complaints of drowsiness for 1 day with a recent history of high grade intermittent fever and generalized erythroderma for preceding 6 days. He had no history of headache, convulsion, vomiting, diarrhoea, sore throat, cough, urinary complaints, trauma, documented hypoglycemia, recent change of medication or recent travel. Along with medications of prevailing chronic co-morbidities, he got injectable ceftriaxone 2 gram/day for 4 days prior to admission.

Clinical examination revealed- GCS as 11 , core temperature- $104^{\mathrm{R}}$ "F, blood pressure as $140 / 70 \mathrm{mmHg}$, pulse as $120 \mathrm{bpm}$, generalized erythroderma distributed more in face, neck and trunk than limbs, congested conjunctiva, healthy sternotomy wound, no lymphadenopathy, no organomegaly and no sign of meningeal irritation with normal deep tendon and planter reflexes.

Initial investigations revealed pancytopenia ( $\mathrm{Hb} \%-11.1$ $\mathrm{mg} / \mathrm{dl}, \mathrm{WBC}-3.2 \times 10^{3} / \mu \mathrm{l}$ with neutrophil $82 \%$, PLatelet$\left.107 \times 10^{3} / \mu \mathrm{l}\right)$, Hyponatremia (Na-123 mmol/L), raised ALT (128 U/L) and AST (86 U/L)), hypoalbuminaemia (22gm/ L), rasied FDP [70 (mg/dl)] and D-dimer [58360 ( $\mu \mathrm{g} / \mathrm{L})]$. Other parameters as PT [13 second (sample)], INR [1.15], APTT-[32.9 (second)], serum procalcitonin [0.9ng/ml], renal function test, urine R/E were normal. ICT for malaria, Dengue, Chlamydia and Viral markers (HBsAg, Anti HCV, CMV IgM-IgG, CMV-PCR, EBV-Ab, HIV 1\& 2) were negative. USG of abdomen showed mild hepatomegaly and chest $\mathrm{x}$-ray detected no radiological abnormality. His blood and urine culture both aerobic and anaerobic detecetd no organism.

During in-hospital course of illness, the patient received empirically injectable broad spectrum antibiotics (including meropenem) along with injectable antiviral (acyclovir) and antifungal (fluconazole) for febrile neutropenia. Despite of supportive treatment with multiple PRBCs, platelet apheresis and G-CSF, pancytopenia worsened progressively ( $\mathrm{Hb}$ : 11.1 to 8.9 gm/dl; WBC: 3.2 to $0.6 \times 10^{3} / \mu \mathrm{l}$; neutrophil $82 \%$ to 32.8 $\%$; platelet 107 to $\left.74 \times 10^{3} / \mu \mathrm{l}\right)$. Serum bilirubin increased from 0.68 to $2.9 \mathrm{mg} / \mathrm{dl}, \mathrm{ALT}: 128$ to $144 \mathrm{U} / \mathrm{L}$ and AST: 86 to $111 \mathrm{U} / \mathrm{L}$ and patient continued to remain febrile with flactuating level of conciouness. CT \& MRI of brain showed mild cerebral atrophy and CSF analysis revealed mononuclear pleocytosis with elevated protein content.

At this stage with precaution and supportive care, bone marrow aspiration was done which revealed as hypocellularity (Fig.-1) with severely depressed erythropoiesis, granulopoiesis. Megakaryocyte were reduce, lymphocytes and plasma cells were prominent with increased number of histocytes and also showed marked haemophagocytosis (Fig.-2)- altogether suggestive of Haemophagocytic syndrome / Haemophagocytic lymphohistocytosis (HLH). Further studies which revealed elevated serum Ferritin (4541 $\mu \mathrm{g} /$ L), Hypofibrinogenaemia(1.07 $\mathrm{gm} / \mathrm{L}$ ) supported the diagnosis of HLH.

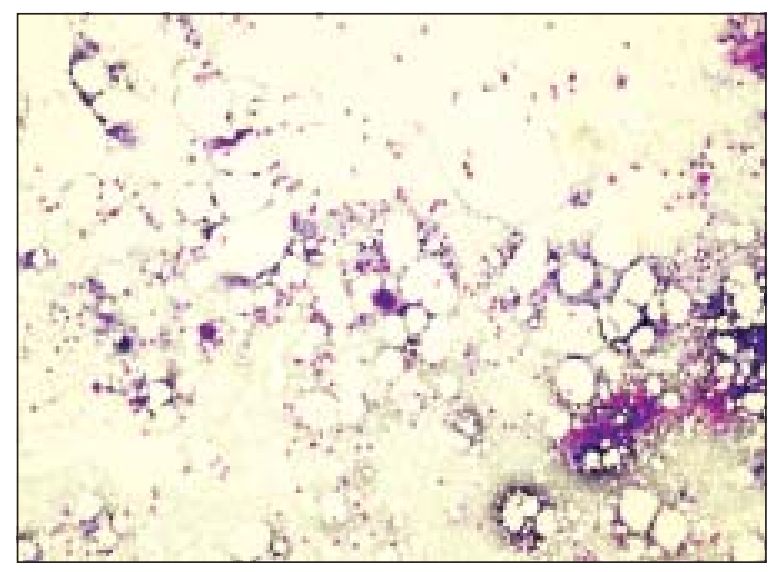

Fig.-1: Low power view of the bone marrow smear of the patient showing hypocellularity.

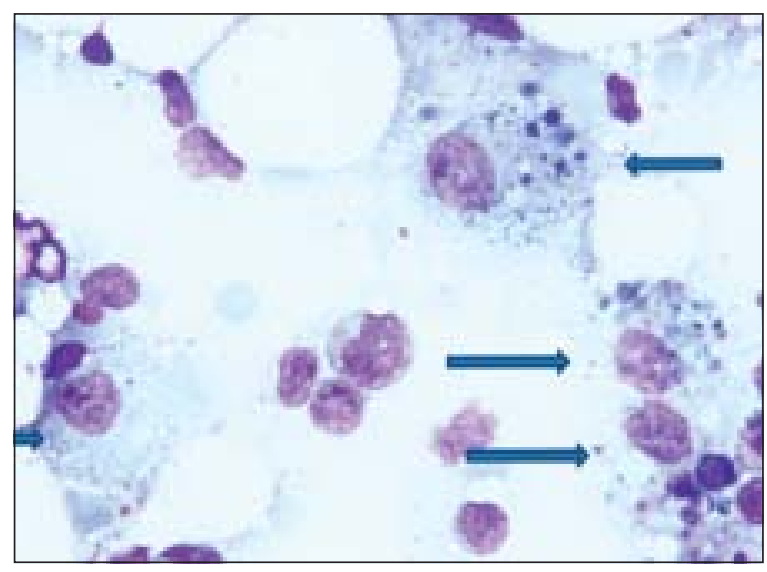

Fig.-2: High power view of the bone marrow smear of the patient showing several macrophages laden with cell debris (arrow) 
Patient fulfilled five of eight diagnostic criteria of HLH including fever, cytopenia, high ferritin, hypofibrinogenaemia and typical bone marrow findings. Therefore treatment according to HLH-2004 protocol was initiated with Etoposide, Dexamethasone, CyclosporineA on the $7^{\text {th }}$ day after admission. Patient remained static during initial three days of chemotherapy but subsequently patient clinical and biochemical parameters deteriorated with all continued supportive treatments. ( progressive pancytopenia: as $\mathrm{Hb}: 9.8$ to $9.3 \mathrm{gm} / \mathrm{dl}$; WBC: 0.6 to $0.03 \times 10^{3} / \mu \mathrm{l}$; neutrophil $32.8 \%$ to $23.5 \%$; platelet 74 to $22.4 \times 10^{3} / \mu \mathrm{l}$ ). Repeated blood and urine cultures were sterile. Repeat serology did not identify any significant viral titre. The clinical condition of the patient further deterioriated with circulatory \& respiratory insufficiency requiring ionotropic support and mechanical ventilation. Despite continued specific and supportive therapy, the patient succumbed to the illness within 12 days of admission and after 5 days of start of chemotherapy.

\section{Discussion:}

HLH encompasses a heterogeneous class of rare but potentially fatal disorders characterized by multi-system inflammation, that occurs due to prolonged and intense activation of antigen- presenting cells (macrophages, histiocytes) and CD8+T-cells, and excessive proliferation and ectopic migration of T-cells ${ }^{19}$ resulting into consumption and apoptosis of various hematologic cell lines. The primary form (FHLH) is an inflammatory disease which is similar to secondary one on the basis of symptoms. Age of onset of this variety is less than one year of age in $70 \%$ of cases but it can rarely be observed in the first two weeks of life. ${ }^{20,21}$ In rare cases, it may occur in adults as well. ${ }^{4}$ Although several types of gene mutations e.g.; PRF 1, UNC 13D, STX 11, RAB27A, STXBP2, SH2D1A, XIAP, LYST etc. have been identified in patients with primary $\mathrm{HLH},{ }^{1,22}$ they all lead to the common phenotype of impaired cytotoxic function by NK and T cells, and a predisposition to develop $\mathrm{HLH}^{23}$

Acquired (secondary) forms of HLH may develop as a result of strong immunological activation of the immune system, which may be caused by a severe infections, rheumatological disorders and malignancies. It generally occurs among older children and adults who present without a family history or known genetic cause. ${ }^{24}$
Leading triggering agents of infection-associated haemophagocytic syndrome (IAHS) are viruses of the herpes group, especially EBV and CMV. ${ }^{24}$ The patients in the original report by Risdull et al. were mostly associated with viral infection following organ transplantation. ${ }^{25}$ Subsequently its association was established with many viruses as well as a number of bacteria, fungi, mycobacteria and parasite and the term Viral Associated Haemophagocytic Syndrome (VAHS) was redesigned as Infection Associated Haemophagocytic Syndrome (IAHS). ${ }^{24}$ A review of published cases in children with IAHS reported that more than half of them were from Far East and Ebstein Barr Virus (EBV) was the triggering virus in $74 \%$ of the children. ${ }^{26}$ Fardet et al reported Human Herpes virus 8 associated HLH among HIV-infected patients. ${ }^{27}$ Malignancy associated acquired HLH (MAHS), with lymphoma being the commonest trigger, is well known entity in adults but rare in children. In a recent review of patients with lymphoma associated haemophagocytic syndrome (LAHS) in Japan showed that EBV genome was detected from more than $80 \%$ of T/NK cell lymphoma but rarely from B cell lymphoma. ${ }^{28}$ Macrophageactivation syndrome (MAS) is a special form of HLH which occurs both in children and adults with autoimmune diseases, ${ }^{29}$ and most commonly seen in association with systemic onset juvenile rheumatoid arthritis (sJRA) or adult onset Still's disease and rarely found with systemic lupus erythematosus or other entities. ${ }^{30,31}$ Clinical picture and laboratory findings are similar to HLH. Patients of sJRA were found to have low NK cell function and perforin expression compared to other form of rheumatoid arthritis. ${ }^{32}$ MAS is a grave disorder with a mortality of about 10-20\%. It has been suggested by some rheumatologists that MAS be classified as a form of secondary HLH. ${ }^{33,34}$

Categorizing patients as having either "primary" or "secondary" HLH at diagnosis is of limited value. Without a known genetic defect or family history, it is often not possible to make an initial diagnosis of "primary" or "secondary" HLH. Furthermore, a careful search for underlying disease triggers should be performed in all patients. However, Recurrence of HLH, in the absence of autoimmune disease or malignancy, is generally considered to be good evidence that a patient has primary HLH. Despite attempts to differentiate primary from secondary HLH, the clinical presentation 
is highly overlapping, hence initial treatment should not be delayed or altered based on these categories. ${ }^{19}$ The clinical picture of HLH is nonspecific and differentiation of HLH from sepsis with disseminated intra vascular coagulation (DIC) can be difficult. Generally, the onset of HLH is acute or subacute, with persistent high-grade fever (e"38,5 $\mathrm{C}$ and e"7 days), anorexia, and weight loss. ${ }^{35,36,37}$ Enlargement of the spleen and liver are often seen in HLH. Rash, jaundice, edema, lymphadenopathy, and cerebro-meningeal symptoms (meningitis, seizures, gait and balance problems, etc) can also be present. ${ }^{35,36,38}$ Lifethreatening multi organ failure is frequently seen in fullpictured HLH. ${ }^{36,}{ }^{37}$ The fever often fluctuates with complete remission and recurrence. Patients may have a variety of skin manifestations, including generalized maculopapular erythematous rashes, generalized erythroderma, edema, panniculitis, morbilliform erythema, petechiae, and purpura. ${ }^{5,39}$ The incidence of skin manifestations ranges from $6 \%-65 \%$ with highly pleomorphic presentations. ${ }^{4,40,7}$ Some patients may present with features suggestive of Kawasaki disease, including erythematous rashes, conjunctivitis, red lips, and enlarged cervical lymph nodes. ${ }^{41}$ The patient in our case report presented with prolonged fever with generalized erythroderma

Patients may develop pulmonary dysfunction which is an ominous sign. In a review of the radiographic abnormalities in 25 patients, 17 had acute respiratory failure with alveolar or interstitial opacities, with fatal outcomes in $88 \%$ of those cases. ${ }^{42}$ Our patient developed acute respiratory failure and needed ICU support including mechanical ventilation.

More than one-third of patients will present with neurologic symptoms, including seizures, meningismus, altered level of consciousness, cranial nerve palsy, psychomotor retardation, ataxia, irritability, or hypotonia. ${ }^{43}$ Patient may have even only neurological manifestations. ${ }^{44,} 45$ The cerebrospinal fluid (CSF) is abnormal in $>50 \%$ of HLH patients with findings of pleocytosis, elevated protein, and/or haemophagocytosis. ${ }^{43}$ MRI findings are variable, including discrete lesions, leptomeningeal enhancement, or global edema, and images correlate with neurologic symptoms ${ }^{46}$ Retinal hemorrhages, swelling of the optic disc and infiltration of the choroid have been reported in infants with $\mathrm{HLH} .{ }^{47,48,49}$ Diffuse peripheral neuropathy with pain and weakness secondary to myelin destruction by macrophages may also occur. ${ }^{50,51}$
The workup for HLH includes a complete and differential blood count, renal function tests, liver function tests, fasting triglycerides, international normalized ratio, partial thromboplastin time, fibrinogen, and ferritin. The most characteristic laboratory findings in HLH are cytopenia affecting e" 2 cell lineages in peripheral blood and hyperferritinemia, often "sky high" $>10,000 \mu \mathrm{g} / \mathrm{L} .{ }^{35}$, 36, 38, 52 Anemia and thrombocytopenia occur in $>80 \%$ of patients at the time of presentation ${ }^{53,54}$ that depends on combination of haemophagocytosis, hypersplenism and massive cytokine release by activated macrophages (e.g., INF à, TNF-á). ${ }^{36,37}$ Thrombocytopenia is almost always present and can lead to severe bleeding, especially in the presence of coagulopathy (e.g., low fibrinogen level). Current case had pancytopenia. Hepatic manifestations of HLH include a moderate increase in serum transaminases, pronounced cholestasis, raised serum bilirubin, decreased serum albumin and coagulation factors deficiency. ${ }^{55}$ Most patients have variable evidence of hepatitis at presentation. 53, 4, 54 Autopsy evaluation study of the liver has shown chronic persistent hepatitis with periportal lymphocytic infiltration in 22 of 27 patients with HLH. ${ }^{56}$ Our reported case had transaminitis. Hypertriglyceridemia, hypofibrinogenemia, elevated serum lactate dehydrogenase, hyponatremia are frequently seen in HLH. ${ }^{35}, 36$ Elevated VLDL and decreased HDL may also be present. ${ }^{35}$ Nearly $95 \%$ of patients have features of disseminated intravascular coagulation and are at high risk for acute bleeding ${ }^{53}$ \& associated with high (>70\%) mortality when present. ${ }^{37}$ Elevated ferritin levels ( $>10,000 \mu \mathrm{g} / \mathrm{L}$ ) are reported to be $90 \%$ sensitive and $96 \%$ specific for HLH in children, ${ }^{57}$ although this has not been validated in adults.

Investigations for secondary triggers of HLH include investigations for viral infections (particularly EBV, HSV, HIV and CMV) and for malignancies as clinically indicated. A search for these etiologic agents was performed in our patient. He was found to be negative for EBV,HSV, HIV, CMV virus. However it should be emphasized that with the possible exception of leishmaniasis, anti-infectious therapy alone is not sufficient to control HLH. A lumbar puncture is also recommended as part of a diagnostic workup, and more than half of patients will have a moderate pleocytosis and/or increased protein content, even in the absence of neurological symptoms. The caution with lumbar puncture must be taken with regard to a possibly increased intracranial pressure. ${ }^{20}$

All patients should have a bone marrow aspiration. However, frank haemophagocytosis may not be 
observed early in the course of the disease, and serial marrow aspirates may be helpful. 58, 59 Haemophagocytosis might be found in the first bone marrow aspiration of a FHLH patient but the absence of it will not rule out this diagnosis. As a result, if the bone marrow is not conclusive, material should be obtained from other organs e.g.; liver, spleen, and lymph nodes 60,56 and occasionally the central nervous system ,61, 62 skin ${ }^{63}$ and serial aspirates over time may also be helpful . 58, 59 In our case, the bone marrow aspiration was performed and it revealed haemophagocytosis. Activated macrophages may engulf erythrocytes, leukocytes, and platelets, their precursors, and cellular fragments. These cells appear "stuffed" with other blood cells. Haemophagocytosis may be present in the liver and infiltration of the hepatic portal tracts with lymphocytes is also common. ${ }^{60,} 56$ Although haemophagocytosis in bone marrow is associated with $\mathrm{HLH}$, the morphologic phenomenon may also be induced by more common events, including blood transfusions, infection, autoimmune disease, and other forms of bone marrow failure or causes of red blood cell destruction .64-66 Despite the nomenclature of HLH, diagnosis should never be made or excluded solely on the presence or absence of haemophagocytosis. Infiltration of bone marrow or liver by activated macrophages, along with global clinical evaluation, may distinguish HLH from other causes of haemophagocytosis. Two highly sensitive diagnostic parameters are low natural killer (NK) cell activity , ${ }^{67-71}$ and a hypercytokinemia, in particular elevated alpha chain of the soluble interleukin2 receptor (sIL-2r) levels (sCD25) ${ }^{71,72}$ in serum and in the CSF . ${ }^{72,73}$ NK cell activity helps to differentiate between reactive form of HLH from familial type. In patients with FHL, NK cell number is normal, but the activity is persistently decreased or absent. Patients with acquired HLH may have low NK cell number; NK cell function is decreased with active disease, but usually reverts to normal after treatment . ${ }^{29}$ The laboratory workup should involve perforin expression by NK cell by using flow cytometry. Patients lacking perforin expression should be analyzed for the PRFI gene mutation, Molecular studies for HLH include mutations in perforin $(P R F)$, Munc 13-4 (UNC13D), syntaxin 11 (STX11), and others can be done at specialized centers.

To assist with the rapid diagnosis of HLH, the Histiocyte Society has developed a set of diagnostic guidelines that encompass both clinical and laboratory findings 35 which are summarized in Table 1.

Table-I

Revised Diagnostic Guidelines for $\mathrm{HLH}$

The diagnosis of HLH can be established if one of either 1 or 2 below is fulfilled

1. A molecular diagnosis consistent with HLH

2. Diagnostic criteria for HLH fulfilled (At least five criteria)

A. Initial diagnostic criteria (to be evaluated in all patients with HLH)

$\square \quad$ Fever

$\square \quad$ Splenomegaly

$\square \quad$ Cytopenias(affecting $\geq 2$ of 3 lineages in the peripheral blood):

- Haemoglobin <90g/L(in infants <4weeks: haemoglobin<100g/L)

- $\quad$ Platelet $<100 \times 10 / \mathrm{L}$

- Neutrophils $<1.0 \times 10 / \mathrm{L}$

$\square$ Hypertriglyceridemia and / or hypofibrinogenemia :

- Fasting triglycerides $\geq 3.0 \mathrm{mmol} / \mathrm{L}$ (i.e $\geq 265 \mathrm{mg} / \mathrm{dl}$ )

- Fibrinogen $\leq 1.5 \mathrm{~g} / \mathrm{L}$

$\square$ Haemophagocytosis in the in bone marrow or spleen or lymph nodes

$\square \quad$ No evidence of malignancy

B. New diagnostic criteria

$\square \quad$ Low or absent NK-cell activity (according to local laboratory references)

$\square \quad$ Ferritin $\geq 500 \mu \mathrm{g} / \mathrm{L}$

$\square \quad$ Soluble CD25 (i.e soluble IL-2 receptor) $\geq 2400 \mathrm{U} / \mathrm{ml}$

N.B: In the absence of a family history or specific molecular diagnosis, at least five diagnostic criteria are needed for a diagnosis of HLH. 
In the absence of a family history or specific molecular diagnosis, an assemblage of at least five of the eight diagnostic criteria are needed for a diagnosis of HLH and initiation of therapy [35]. At the end after ruling out other diagnoses and considering the fact that our patient had five criteria for HLH (fever, pancytopenia, hyperferritinemia, hypofibrinogenemia and Haemophagocytosis in bone marrow ), we decided that $\mathrm{HLH}$ is the most probable diagnosis. It is important to consider the fact that none of these eight criteria are specific for HLH diagnosis and might be found in sepsis, SIRS and MODS. ${ }^{74-76}$ For example the etiology of hypertriglyceridemia in these states can be multifactorial such as insulin resistance ${ }^{77,78}$ and inhibition of lipoprotein lipase activity. ${ }^{79,80}$ High level of serum ferritin has also been associated with inflammatory states and is frequently seen in toxic patients due to the up regulation of hemoxygenase- 1 (heat shock protein). ${ }^{81}$, ${ }^{82}$ Ferritin is also an anti-apoptotic agent in ischemiareperfusion injury ${ }^{83}$ Elevated soluble IL-2 receptor (CD25) is also observed in sepsis, SIRS and can be a predictive marker in neonatal sepsis. ${ }^{84,85}$ Similar to HLH disease, NK-cell activity is also decreased in sepsis and thermal injury. ${ }^{86}$

The therapy of any form of HLH should focus on: (1) suppression of the life-threatening hyper-inflammatory status by destruction of activated CD8+ T lymphocytes and macrophages, and (2) treatment of any existing HLH triggers. $35,36,87,52$ In cases of FHL, an additional aim is

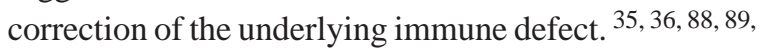
90 The first prospective international treatment protocol for HLH (HLH-94) was introduced in 1994. ${ }^{91}$ The experience gained from this protocol and other studies have led to the development of a new treatment protocol, HLH-2004 (including etoposide, dexamethasone and CyA).$^{35}$ Current international HLH 2004 protocol is designed for all patients with newly diagnosed HLH, with or without evidence of familial or genetic disease, and regardless of suspected or documented infection. ${ }^{35}$ The protocol represents systemic chemoimmunotherapy including dexamethasone, cyclosporine A, etoposide and, in selected patients, intrathecal therapy with methotrexate. Corticosteroids show cytotoxic effect and inhibit expression on cytokines. Cyclosporine A prevents T-lymphocyte activation. Etoposide is an anti-neoplastic agent highly effective in monocytic and histiocytic disorders. Intrathecal methotrexate is used only in patients with persistently abnormal cerebrospinal fluid or progressive neurological symptoms and CNS reactivation. ${ }^{35}$

In genetic HLH the ultimate aim must be hematopoietic stem cell transplantation (HSCT) to replace congenitally defective immune system with normal functioning immune effectors cells of healthy donors. However, in the vast majority of FHL cases immuno-chemotherapy with HLH-94 or HLH-2004 protocols is temporarily effective in the control of disease, and the outcome of FHL is uniformly fatal unless the patient undergoes allogeneic stem cell transplantation (allo-SCT) . ${ }^{35,89,90}$ Treatment of sHLH is not standardized so far and remains highly variable across the centers. Obviously, if possible, treatment of any existing trigger of HLH is a must. Front line treatment of infection associated HLH and MAS (particularly of milder grades) usually involves corticosteroids (as in HLH-94 and HLH-2004 protocols) with or without intravenous immunoglobulin (IVIG), which may be sufficient to control hyperinflammation .${ }^{36}$ After improvement of complete blood count and resolution of coagulopathy, steroids are slowly tapered down to avoid relapses. ${ }^{36,92}$ Patients with viralassociated haemophagocytic syndrome should receive appropriate anti-viral therapy such as ganciclovir for CMV. Other interventions include supportive therapy with antimicrobial prophylaxis and intravenous immunoglobulins (IVIg).$^{93,35}$ Emmenegger and others had evidence that IVIG is effective in the treatment of HLH . ${ }^{94,95}$ A key finding of their analysis was that efficacy of IVIG was satisfactory if administered at the beginning (within hours) of the macrophage activation process. Rituximab, an anti-CD20 monoclonal antibody, has been used to suppress EBV- infected B cells in HLH.${ }^{96}$ The utility of biological response modifiers, such as TNF-á inhibitors, IL-1 inhibitors, IL-6 inhibitors, or anti-CD52 antibodies remains unclear. Available case reports have conflicting results, and at present time there is no consensus on recommendations in respect to this group of drugs in HLH . ${ }^{97-101}$ Finally, anecdotal reports have also shown the efficacy of allo-SCT in refractory or recurrent sHLH (e.g., EBV-HLH, M-HLH) . ${ }^{102-107}$ Acquired HLH, even when treated in a timely manner, can be fatal and deaths being reported among patients treated with massive doses of steroids.$^{92}$ However, corticosteroid resistant non-responders may benefit from second-line therapies, such as CyA ${ }^{87}$ If there is 
no response to aforementioned drugs, use of the HLH2004 protocol including etoposide is recommended.$^{35}$, $36,38,1$ In summary, patients with sHLH could be started on therapy without etoposide, as long as treatment adjustments are made rapidly in refractory cases ${ }^{87}$ Initial treatment is given for eight weeks, and patients with persistent disease or an underlying genetic abnormality (primary HLH) should go on to continuation therapy as a bridge to allogeneic stem cell transplantation. In patients with poor performance status and multi-organ dysfunction, palliation is reasonable.$^{108}$

Although symptoms and laboratory features improve within 2 to 3 weeks, in some cases cytopenia may persist. In these cases bone marrow examination should be repeated to differentiate between non-response and myelosuppression due to etoposide. If there is no response, then unlikely to have benefit with medical treatment. There is no established salvage regimen. Isolated patient has responded to daclizumab, alemtuzumab or to stem cell transplantation. Hasegawa et al reported remission of HLH after syngenic bone marrow transplantation..$^{109}$

Despite treatment, the prognosis of both familial and acquired forms of HLH is usually poor and is rapidly fatal in untreated cases. The CNS disease can cause relapses and may results into irreversible disability. Since HLH can be rapidly fatal without specific intervention, it is recommended that treatment be started when there is a high clinical suspicion, even when results of some diagnostic studies are still pending.

\section{Conclusion:}

HLH is a life-threatening hyper-inflammatory syndrome which remains difficult to diagnose and can be easily overlooked or misdiagnosed. The clinical features can mimic the multi-system involvement seen in severe sepsis or malignancy. The presenting features are so indistinct that unless definitive criteria are actively sought, many cases may go unrecognized or be recorded as sepsis. Early establishment of the diagnosis is very important for timely commencement of the treatment, before overwhelming disease activity makes irreversible damage and a response to treatment becomes less likely. Despite treatment, the prognosis of both familial and acquired forms of HLH is usually poor and is rapidly fatal in untreated cases.

\section{Rerefences:}

1. Jordan MB, Allen CE, Weitzman S, Filipovich AH, McClain KL. How I treat haemophagocytic lymphohistiocytosis. Blood. 2011 Oct 13;118(15): 4041-52.

2. Henter J-I, Arico M, Elinder G, et al. Familial haemophagocytic lymphohistiocytosis (primary HLH). Hematol Oncol Clin North Am 1998;12:417-433.

3. Janka G, Elinder G, Imashuku S, et al. Infection- and malignancy associated haemophagocytic syndromes: Secondary haemophagocytic lymphohistiocytosis. Hematol Oncol Clin North Am 1998;12: 435-444.

4. Arico M, Janka G, Fischer A, Henter JI, Blanche S, Elinder G, et al. Haemophagocytic lymphohistiocytosis. Report of 122 children from the International Registry. FHL Study Group of the Histiocyte Society. Leukemia. 1996 Feb;10(2):197-203.

5. Farquhar J, Claireaux A. Familial haemophagocytic reticulosis. Arch Dis Child 1952;27:519-25.

6. Henter J-I, Soder $\mathrm{O}$, et al. Incidence and clinical features of familial haemophagocytic lymphohistiocytosis in Sweden. Acta Paediatr Scand 1991;80:428-435.

7. Janka GE. Familial haemophagocytic lymphohistiocytosis. Eur J Pediatr 1983;140:221-230.

8. Henter JI, Ehrnst A, Andersson J, et al. Familial haemophagocytic lymphohistiocytosis and viral infections. Acta Paediatr 1993;82: 369-372.

9. Wong KF, Hui PK, Chan JK, Chan YW, Ha SY. The acute lupus haemophagocytic syndrome. Ann Intern Med 1991;114:387-90.

10. Kumakura S, Ishikura H, Munemasa S, Adachi T, Murakawa Y, Kobayashi S. Adult onset Still's disease associated haemophagocytosis. J Rheumatol 1997;24:1645-8.

11. Morris JA, Adamson AR, Holt PJ, Davson J. Still's disease and the virus-associated haemophagocytic syndrome. Ann Rheumatol Dis 1985;44:349-53

12. Yasuda S, Tsutsumi A, Nakabayashi T, Horita T, Ichikawa $\mathrm{K}$, Ieko M, et al. Haemophagocytic syndrome in a patient with dermatomyositis. Br J Rheumatol 1998;37:1357-8.

13. Chang CS, Wang CH, Su I J , Chen YC, Shen MC. Hematophagic histiocytosis: a clinicopathologic analysis of 23 cases with special reference to the association with peripheral T-cell lymphoma. J Formos Med Assoc 1994;93:421-8.

14. Kadin ME, Kamoun M, Lamberg J. Erythrophagocytic T gamma lymphoma: a clinicopathologic entity resembling malignant histiocytosis. N Engl J Med 1981;304: 648-53.

15. Yao M, Cheng A, Su I. Clinicopathological spectrum of haemophagocytic syndrome in Epstein-Barr virusassociated peripheral T-cell lymphoma. Br J Haematol 1994;87:535-43. 
16. Gutiérrez A, Solano C, Ferrández A, Marugán I, Terol MJ, Benet I, Tormo M, Bea MD, Rodríguez J. Peripheral Tcell lymphoma associated consecutively with haemophagocytic lymphohistiocytosis and hypereosinophilic syndrome. Eur J Haematol 2003;71:303-6.

17. Yang CW, Pan MJ, Wu MS, Chen YM, Tsen YT, Lin CL, et al. Leptospirosis: an ignored cause of acute renal failure in Taiwan. Am J Kidney Dis 1997;30:840-5.

18. Matzner Y, Behar A, Beeri E, Gunders A, Hershko C. Systemic leishmaniasis mimicking malignant histiocytosis. Cancer 1979;43:398-402.

19. Filipovich AH. Haemophagocytic lymphohistocytosis and other haemophagocytic disorders. Immunol Allergy Clin North Am 2008; 28: 293 -313.

20. Lazkowsky p. Hystocytosis syndrome. In: Lazkowsky P. Manual of pediatric hematology\&oncology. $4^{\text {th }}$ ed.Newyork : Academic press 2006: 604-29.

21. Levendoglu-Tugal O, Ozkaynak MF, LaGamma E, Sherbany A, Sandoval C, Jayabose S. Haemophagocytic lymphohistiocytosis presenting with thrombocytopenia in the newborn. J Pediatr Hematol Oncol 2002;24:405-9.

22. Michael B. Jordan, Cari E. Aiien, Sheila Weitzman, Aiexandra H. Filipovich and Kenneth L. McClain. How I treat Haemophagocytic lymphohistocytosis. Blood Journal 2011; 118: 4041-4052

23. Feldmann J, Callebaut I, Raposo G, et al. Munc13-4 is essential for cytolytic granules fusion and is mutated in a form of familial haemophagocytic lymphohistiocytosis (FHL3). Cell 2003;115:461-473.

24. Fisman DN. Haemophagocytic syndromes and infection. Emerg Infect Dis 2000;6(6):601-608.

25. Risdall RJ, McKenna RW, Nesbit ME, et al. Virus associated haemophagocytic syndrome: a benign histiocytic proliferation distinct from malignant histiocytosis. Cancer 1979;44: 993-1002.

26. Janka G, Imashuku S, Elinder G, SchneidernM Henter JL. Infection and malignancy associated haemophagocytic syndrome. Secondary haemophagocytic lymphohistiocytosis. Hematol Oncol Clin North Am 1998;12 :435-444.

27. Fardet, L Blum,, D. Kerob, F. Agbalika, L. Galicier, A. Dupuy et al. Human Herpesvirus 8 associated Haemophagocytic Lympho Histiocytosis in Human Immunodeficiency Virus Infected patients. Clinical Infectious Disease 2003;37:285-91.

28. Takahashi N, Chubachi A, Miura I, Nakamura S, Miura AB. Lymphoma associated haemophagocytic syndroms in Japan. Rinsho Ketsueki 1999;40:542-9.

29. Janka GE. Haemophagocytic Syndromes. Blood Rev 2007; 21: 245-53.
30. Stephan Jl, Kone-Paut I, Galambrun C, Mouy R, BaderMeunier B, Prieur AM. Reactive haemophagocytic syndrome in children with inflammatory disorders. A retrospective study of 24 patients. Rheumatology 2001; 40:1285-92.

31. Ravelli A. Macrophage activation syndrome. Curr Opin Rheumatol 2002;14:548-52.

32. Villanueva J, Lee S, Giannini EH, et al. Natural killer cell dysfunction is adistinguishing feature of systemic onset juvenile rheumatoid arthritis and macrophage activation syndrome. Arthritis Res Ther 2005;7:R30-37.

33. Ramanan AV, Schneider R. Macrophage activation syndrome- what's in a name! J Rheumatol 2003;30: 2513-6.

34. Athreya $\mathrm{BH}$. Is macrophage activation syndrome a new entity? Clin Exp Rheumatol 2002;20:121-3.

35. Henter J.-I., Horne A., Arico M. et al.: HLH-2004: Diagnostic and therapeutic guidelines for haemophagocytic lymphohistiocytosis. Pediatr. Blood Cancer 2007; 48: 124-31.

36. Janka G.: Haemophagocytic lymphohistiocytosis: When the immune system runs amok. Clin. Padiatr 2009; 221: 278-85

37. Karras A.: What nephrologists need to know about haemophagocytic syndrome. Nat. Rev. Nephrol 2009; 5: 329-36.

38. Machaczka M., Vaktnäs J., Klimkowska M., Hägglund H.: Malignancy-associated haemophagocytic lymphohistiocytosis in adults: a retrospective population-based analysis from a single center. Leuk. Lymphoma 2011; 52: 613-9.

39. Morrell DS, Pepping MA, Scott JP, Esterly NB, Drolet BA. Cutaneous manifestations of haemophagocytic lymphohistiocytosis. Arch Dermatol 2002;138(9):1208-1212.

40. Henter JI, Elinder G, Soder O, Ost A. Incidence in Sweden and clinical features of familial haemophagocytic lymphohistiocytosis. Acta Paediatr Scand 1991;80(4):428-435.

41. Palazzi DL, McClain KL, Kaplan SL. Haemophagocytic syndrome after Kawasaki disease. Pediatr Infect Dis J 2003;22(7):663-666.

42. Fitzgerald N, McClain KL. Imaging characteristics of haemophagocytic lymphohistiocytosis. Pediatr Radiol 2003;33:392-401.

43. Horne A, Trottestam H, Arico M, et al. Frequency and spectrum of central nervous system involvement in 193 children with haemophagocytic lymphohistiocytosis. $\mathrm{Br}$ J Haematol 2008;140(3):327-335.

44. Henter JI, Elinder G. Cerebromeningeal haemophagocytic lymphohistiocytosis. Lancet 1992;339:104-7. 
45. Kieslich M, Vecchi M, Driever Ph, Laverda AM, Schwabe D,Jacobi G. Acute encephalopathy as aprimary manifestation of haemophagocytic lymphohistiocytosis. Dev Med Child Neurol 2001;43:555-8.

46. Goo HW, Weon YC. A spectrum of neuroradiological findings in children with haemophagocytic lymphohistiocytosis. Pediatr Radiol 2007;37(11): 1110-1117.

47. Liao PM, Thompson JT. Ophthalmic manifestations of virus-associated haemophagocytic syndrome. Arch Ophthalmol 1991;109(6):777.

48. Park JK, Palexas GN, Streeten BW, Green WR. Ocular involvement in familial erythrophagocytic lymphohistiocytosis. Graefes Arch Clin Exp Ophthalmol 1997;235(10):647-652.

49. Petersen RA, Kuwabara T. Ocular manifestations of familial lymphohistiocytosis. Arch Ophthalmol 1968;79(4):413-416.

50. Boutin B, Routon MC, Rocchiccioli F, et al. Peripheral neuropathy associated with erythrophagocytic lymphohistiocytosis. J Neurol Neurosurg Psychiatry 1988;51(2):291-294.

51. De Armas R, Sindou P, Gelot A, Routon MC, Ponsot G, Vallat JM. Demyelinating peripheral neuropathy associated with haemophagocytic lymphohistiocytosis: an immunoelectron microscopic study. Acta Neuropathol 2004;108(4):341-344

52. Filipovich A.H.: The expanding spectrum of haemophagocytic lymphohistiocytosis. Curr. Opin. Allergy Clin. Immunol 2011; 11: 512-6.

53. Palazzi DL, McClain KL, Kaplan SL. Haemophagocytic syndrome in children: an important diagnostic consideration in fever of unknown origin. Clin Infect Dis 2003;36(3):306-312.

54. Niece JA, Rogers ZR, Ahmad N, Langevin AM, McClain KL. Haemophagocytic lymphohistiocytosis in Texas: observations on ethnicity and race. Pediatr Blood Cancer 2010;54(3):424-428.

55. de Kerguenec C, Hillaire S, Molinie V, Gardin C, Degott C, Erlinger S, et al. Hepatic manifestations of haemophagocytic syndrome: a study of 30 cases. Am J Gastroenterol 2001;96(3):852-7.

56. Ost A, Nilsson-Ardnor S, Henter JI. Autopsy findings in 27 children with haemophagocytic lymphohistiocytosis. Histopathology1998;32(4):310-316.

57. Allen CE, Yu X, Kozinetz CA, McClain KL. Highly elevated ferritin levels and the diagnosis of haemophagocytic lymphohistiocytosis. Pediatr Blood Cancer 2008; 50 (6):1227-35.

58. Gupta A, Weitzman S, Abdelhaleem M. The role of haemophagocytosis in bone marrow aspirates in the diagnosis of haemophagocytic lymphohistocytosis. Pediatr Blood Cancer 2008 Feb; 50: 192-194.

59. Gupta A, Tyrrell P, Valani R, Benseler S, Weitzman S, Abdelhaleem M. Pediatr Blood Cancer 2008; 51: 402-404.

60. Favara B. Haemophagocytic lymphohistiocytosis: a haemophagocytic syndrome. Semin Diagn Pathol 1992;9:63-74.

61. Henter J, Nennesmo I. Neuropathologic findings and neurologic symptoms in twenty-three children with haemophagocytic lymphohistiocytosis. J Pediatr 1997;130:358-65.

62. Martin J, Cras P. Familial erythrophagocytic lymphohistiocytosis: a neuropathological study. Acta Neuropathol 1985;66:140-4.

63. Smith K, Skelton H, Yeager J, Angritt P, Wagner K, James W, et al. Military Medical Consortium for Applied Retroviral Research. Cutaneous histopathologic, immunohistochemical, and clinical manifestations in patients with haemophagocytic syndrome. Arch Dermatol 1992; 128:193-200.

64. Schaer DJ, Schaer CA, Schoedon G, Imhof A, Kurrer MO. Haemophagocytic macrophages onstitute a major compartment of heme oxygenase expression in sepsis. Eur J Haematol 2006; 77(5):432-436.

65. Biondi CS, Cotorruelo CM, Ensinck A, Racca LL, Racca AL. Use of the erythrophagocytosis assay for predicting the clinical consequences of immune blood cell destruction. Clin Lab 2004; 50(5):265-270.

66. Kraus MD, Bartlett NL, Fleming MD, Dorfman DM. Splenic pathology in myelodysplasia: a report of 13 cases with clinical correlation. Am J Surg Pathol 1998;22(10):1255-1266.

67. Ladisch S, Poplack DG, Holiman B, et al. Immunodeficiency in familial erythrophagocytic lymphohistiocytosis. Lancet 1978;1: 581-583.

68. Perez N, Virelizier J, Arenzana-Seisdedos F, et al. Impaired natural killer cell activity in lymphohistiocytosis syndrome. J Pediatr 1984;104:569-573.

69. Sullivan KE, Delaat CA, Douglas SD, et al. Defective natural killer cell function in patients with haemophagocytic lymphohistiocytosis and in first degree relatives. Pediatr Res 1998;44:465-468.

70. Kogawa K, Lee SM, Villanueva J, et al. Perforin expression in cytotoxic lymphocytes 2002;99: 61-66

71. Schneider EM, Lorenz I, Mu“ller-Rosenberger M, et al. Haemophagocytic lymphohistiocytosis (HLH) is associated with deficiencies of cellular cytolysis but normal expression of transcripts relevant to killer cell induced apoptosis. Blood 2002;100:2891- 2898. 
72. Komp DM, McNamara J, Buckley P. Elevated soluble interleukin-2 receptor in childhood haemophagocytic histiocytic syndromes. Blood 1989;73:2128-2132.

73. Henter J-I, Elinder G, So“der O, et al. Hypercytokinemia in familial haemophagocytic lymphohistiocytosis. Blood 1991;78:2918-2922.

74. Castillo L, Carcillo J. Secondary. Haemophagocytic lymphohistiocytosis and sever sepsis/systemic inflammatory response syndrome/multiorgan dysfunction syndrome/macrophage activation syndrome share common intermediate phenotypes on a spectrum of inflammation. Pediatr Crit Care Med 2009; 10:387-92.

75. Karapinar B, Yilmaz D, Balkan C, Akin M, Ay Y, Kvakli K. An unusual cause of multiple organ dysfunction syndrome in the pediatric intensive care unit : Haemophagocytic Lymphohistocytosis. Pediatr Crit Care Med 2009; 10:285- 91.

76. Gupta A, Tyrrell P, Valani R, Benselar S, Abdelhaleem M, Weitzman S. Experience with haemophagocytic lymphohistocytosis/ Macrophage activation syndrome at a single institution. J Pediatr Hematol Oncol 2009; 31:81-5.

77. Samra JS, Summers LK, Frayn KN. Sepsis and fat metabolism. Br J Surg 1996; 83: 1186-96.

78. Wendel M, Paul R, Heller AR. Lipoproteins in inflammation and sepsis. II. Clinical aspects. Intensive Care Med 2007;33:25-35.

79. Crouser ED, Julian MW, Huff JE, Mandich DV, GreenChurch KB. A proteomic analysis of liver mitochondria during acute endotoxemia. Intensive Care Med 2006; 32: 1252-62.

80. Murch O, Collin M, Hinds CJ, Thiemermann C.Lipoproteins in inflammation and sepsis. I. Basic science. Intensive Care Med 2007;33:13-24.

81. Abraham NG, Drummond G. CD163-Mediated hemoglobin -home uptake activates macrophage HO-1, providing and antiinflamatory function. Circ Res 2006; 99:911-4.

82. Otterbein LE, Soares MP, Yamashita K, Bach FH. Hemeoxygenase-1: unleashing the protective properties of heme.Trends Immunol 2003;24:449-55.

83. Berberat PO, Katori M, Kaczmarek E, Anselmo D, Lassman C, Ke B et al. Heavy chain ferritin acts as an antiapoptotic gene that protects livers from ischemia reperfusion injury. FASEB J. 2003;17:1724-6.

84. Bleesing J, Prada A, Siegel DM, Villanueva J, Olson J, Ilowite NT et al. The diagnostic significance of soluble CD163 and soluble interleukin-2 receptor alpha-chain in macrophage activation syndrome and untreated new-onset systemic juvenile idiopathic arthritis. Arthritis Rheum 2007;56:965-71.
85. Takala A, Jousela I, Jansson SE, Olkkola KT, Takkunen O, Orpana A et al. Markers of systemic inflammation predicting organ failure in community-acquired septic shock. Clin Sci (Lond) 1999;97: 529-38.

86. Blazar BA, Rodrick ML, O’Mahony JB, Wood JJ, Bessey PQ, Wilmore DW et al. Suppression of natural killer-cell function in humans following thermal and traumatic injury. J Clin Immunol 1986;6:26-36.

87. Gupta S., Weitzman S.: Primary and secondary haemophagocytic lymphohistiocytosis: clinical features, pathogenesis and therapy. Clin Immunol 2010; 6: 137-54.

88. Filipovich A.H.: Haemophagocytic lymphohistiocytosis $(\mathrm{HLH})$ and related disorders. Hematology Am. Soc. Hematol. Educ. Program 2009: 127-31.

89. Jordan M.B., Filipovich A.H.: Hematopoietic cell transplantation for haemophagocytic lymphohistiocytosis: a journey of a thousand miles begins with a single (big) step. Bone Marrow Transplant 2008; 42: 433-7.

90. Marsh R.A., Jordan M.B., Filipovich A.H.: Reducedintensity conditioning haematopoietic cell transplantation for haemophagocytic lymphohistiocytosis: an important step forward. Br J Haematol 2011; 154: 556-63.

91. Henter JI, Arico M, Egeler RM, et al. HLH-94: a treatment protocol for haemophagocytic lymphohistiocytosis. HLH study Group of the Histiocyte Society. Med Pediatr Oncol 1997;28(5):342-347.

92. Filipovich A., McClain K., Grom A.: Histiocytic disorders: recent insights into pathophysiology and practical guidelines. Biol. Blood Marrow Transplant 2010; 16 (1): S82-9.

93. Maakaroun NR, Moanna A, Jacob JT, Albrecht H. Viral infections associated with haemophagocytic syndrome. Rev Med Virol 2010;20(2):93-105.

94. Emmenegger U, Frey U, Reimers A, et al. Hyperferritinemia as indicator for intravenous immunoglobulin treatment in reactive macrophage activation syndromes. Am J Hematol 2001;68:4-10.

95. Larroche C, Bruneel F, André MH, et al. Intravenously administered gamma-globulins in reactive hemaphagocytic syndrome: Multicenter study to assess their importance, by the immunoglobulins group of experts of CEDIT of the AP-HP. Ann Med Intern 2000;151:533-9.

96. Balamuth N.J., Nichols K.E., Paessler M., Taechey D.T.: Use of rituximab in conjunction with immunosuppressive chemotherapy as a novel therapy for Epstein-Barr virusassociated haemophagocytic lymphohistiocytosis. J Pediatr Hematol Oncol 2007; 29: 569-73.

97. Machaczka M., Vaktnäs J., Chiang SC, Bryceson YT. Alemtuzumab treatment for haemophagocytic lymphohistiocytosis. Nat Rev Clin Oncol 2010; 7:10.

98. Strout M.P., Seropian S., Berliner N.: Alemtuzumab as a bridge to allogeneic SCT in atypical haemophagocytic 
lymphohistiocytosis. Nat Rev Clin Oncol 2010; 7: 415-20.

99. Makay B., Yilmaz S., Türkyilmaz Z. et al.: Etanercept for therapy-resistant macrophage activation syndrome. Pediatr Blood Cancer 2008; 50: 419-21.

100. Sandhu C., Chesney A., Piliotis E. et al.: Macrophage activation syndrome after etanercept treatment. J Rheumatol 2007; 34: 241-2.

101. Sellmer A., Stausbol-Gron B., Krag-Olsen B., Herlin T.: Successful use of infliximab in macrophage activation syndrome with severe CNS involvement. Scand J Rheumatol 2010; 40: 156-7.

102. Machaczka M., Nahi H., Karbach H. et al.: Successful treatment of recurrent malignancy-associated haemophagocytic lymphohistiocytosis with a modified HLH-94 immunochemotherapy and allogeneic stem cell transplantation. Med Oncol 2011: 29 [Epub ahead of print]. DOI:10.1007/s12032-011- 9963-3

103. Goi K., Sugita K., Nakamura M. et al.: Development of acute lymphoblastic leukemia with $\mathrm{t}(4 ; 11)$ in a girl with familial pericentric inv 12. Cancer Genet Cytogenet 1999; 110: 124-7.

104. Chang Y.H., Lu P.J., Lu M.Y. et al.: Sequential transplants for respective relapse of Hodgkin disease and HLH: a treatment dilemma. J Pediatr Hematol Oncol 2009; 31: 778-81.

105. Ohga S., Kudo K., Ishii E. et al.: Hematopoietic stem cell transplantation for familial haemophagocytic lymphohistiocytosis and Epstein-Barr virus-associated haemophagocytic lymphohistiocytosis in Japan. Pediatr Blood Cancer 2010; 54: 299-306.

106. Yoon H.S., Im H.J., Moon H.N. et al.: The outcome of hematopoietic stem cell transplantation in Korean children with haemophagocytic lymphohistiocytosis. Pediatr Transplant 2010; 14: 735-40.

107. Kelly C., Salvi S., McClain K., Hayani A.: Haemophagocytic lymphohistiocytosis associated with precursor B acute lymphoblastic leukemia. Pediatr Blood Cancer 2011; 56: 658-60.

108. Takahashi N, Chubachi A, Kume M, Hatano Y, Komatsuda A, Kawabata Y, et al. A clinical analysis of 52 adult patients with haemophagocytic syndrome: the prognostic significance of the underlying diseases. Int $\mathrm{J}$ Hematol 2001;74(2):209-13.

109. Hasegawa D, Sano K, KosakaY, Hayakawa A, Nakamura H. A case of haemophagocytic lymphohistiocytosis with prolonged remission after syngenic bone marrow transplantation, Bone Marrow Transplantation 1999; 24: 425-7. 